\title{
Los diccionarios enciclopédicos del español actual
}

\author{
Inmaculada Anaya Revuelta \\ Universidad de Vigo
}

\section{BREVE HISTORIA: DEL DICCIONARIO A LA ENCICLOPEDIA}

Entre el diccionario de lengua y la enciclopedia existe una obra caracterizada por la mezcla de las características de una y otra: el diccionario enciclopédico. En el diccionario enciclopédico encontramos una mayor amplitud de criterios en lo que al inventario léxico se refiere; se trata de un criterio más orientado hacia el uso que hacia lo normativo.

Dentro de esta concepción, el siglo XIX da paso a la producción de una serie de diccionarios diferentes al de la Academia, y en consecuencia, a un nuevo concepto de diccionario de lengua. Como han señalado algunos autores, entre los que destaca Dolores Azorín (1996-1997: 116), el camino emprendido por Núñez de Taboada, Pla y Torres, Peñalver, Labernia, Eduardo Chao, Salvá, Adolfo de Castro, Ramón Joaquín Domínguez, y algunos más, dio como resultado el desarrollo del diccionario enciclopédico. Concretamente, el Diccionario enciclopédico de la lengua española de Eduardo Chao (1853-1855), es el primero que registra la denominación de "enciclopédico" en el título.

En otro momento nos hemos referido a la dificultad que conlleva la diferenciación entre el significado lingüístico y la realidad extralingüística. En defensa de esta distinción se alza la semántica estructural, que es el máximo exponente en lo que al reconocimiento de la distinción entre el diccionario de lengua y la enciclopedia se refiere. L. F. Lara (1990: 214) afirma que para el estructuralismo, el léxico no debe entenderse como una nomenclatura de referentes del mundo sensible, 
sino "como un juego bien organizado de relaciones entre las palabras, que llega a definir por sí mismo sus significados, en independencia de sus referentes". Desde esta perspectiva, los diccionarios de lengua se orientan hacia las palabras, y los diccionarios enciclopédicos se orien$\tan$ hacia las cosas. En consecuencia, los signos lingüísticos que aparecen en el diccionario de lengua deben ser definidos desde una perspectiva estrictamente lingüística, sin apelar al conocimiento extralingüístico que el lexicógrafo tenga de la realidad.

Frente a estos criterios, encontramos que los diccionarios, obras dirigidas a un público muy numeroso, se ofrecen como instrumentos en los que se compilan todos los saberes. Por otra parte, es común a todas las épocas del idioma el afán por dar la información más exhaustiva de las palabras que aparecen como lemas. Antes del siglo XIX se habían dado algunas muestras indudables del enciclopedismo en las obras lexicográficas. En el Tesoro de la lengua castellana o española (Madrid, 1611), de Covarrubias, leemos:

Arandela. 'Una defensa de la mano derecha que se clava en lo gruesso de la lança de hombres de armas, para defensa de la mano en forma de un embudo. Pudo traer el nombre de la ciudad de Arandel, in Inglaterra, cabeça de Condado de aquel reyno, por averse traydo de allí esta invención, y un género de cuello liso que lo usan las mugeres llaman arandela, por la semejança que le tiene'.

Aranjuez. 'Pago deleitoso en la ribera de Tajo, bien conocido por tener allí el Rey nuestro señor gran recreación de huertas, jardines, caça y pesca y pastos. El padre Guadix dize vale tanto como las yeguas del exército o la tropa de yeguas. Pudo ser que en tiempo de moros se criassen allí en abundancia por tener buen pasto. Para encarecer la amenidad de algún lugar de recreación dezimos es un Aranjuez. Tamarid dize que vale casa de los nogales'.

Otro de los autores más representativos, en lo que al carácter enciclopédico de su obra se refiere, es el P. Esteban de Terreros y Pando que con su Diccionario castellano con las voces de ciencias y artes y sus correspondientes en las tres lenguas francesa, latina e italiana, (1786-1793), incorpora un buen número de tecnicismos y de explica- 
ciones de carácter enciclopédico al Corpus de la Academia. Se trata de un diccionario general de la lengua enriquecido con un buen número de términos científicos y técnicos, además de nombres propios y topónimos. Hemos recogido algunas definiciones de su obra como muestra de que la separación entre lo lingüístico y lo real no aparecía de una manera clara entre los primeros lexicógrafos:

Barcelona. 'Ciudad Capital del Principado de Cataluña, casi al Oriente de España...'

Janno. 'Según toda apariencia, significó en la antigüedad Castellana lo mismo que Enero, atribuyendole dos caras, como á Jano, una con que miraba al año que acababa, volviendo la otra al que empezaba: hallase la voz Janno en un Albalá Real á favor de Ferran de Vihena año de 1111, en el cual reinaba en Castilla Alfonso VIII, que se llamó Emperador. El orijinal del Albalá se halla en pergamino en el Archivo del Conde de Cheles'.

Pleuritis. 'Dolor de costado, enfermedad peligosa, y muchas veces mortal'.

Plus Ultra. 'Divisa de Cárlos V para mostrar despues de la conquista de Tunez el año 1535, que habia hecho mas que Hércules, que no pasó el estrecho que Cárlos V para ir á la Africa. Fr. y Lat. Plus ultra. De modo que la divisa de Hércules eran dos montes figurados con dos colunas, y esta letra, Non plus ultra, y en la de Cárlos se quita el non quedando el plus ultra, más alla, mas adelante'.

Pluto. 'Dios de la felicidad, y riqueza'.

El momento álgido de esta nueva corriente surgida en paralelo a la Academia hay que situarlo, como queda dicho, en el siglo XIX, y en los autores citados anteriormente. Para D. Azorín (1994-1995: 12), el origen de este movimiento lexicográfico estuvo presidido por intereses marcadamente comerciales, lo cual explica, en cierta medida, el oportunismo y la escasa calidad de algunos de sus productos. Pero además de este afán comercial, hubo otro no menos notorio, el afán de criticar a la Academia. Vicente Salvá, uno de los mejores representantes de la época, dirigió una severa crítica contra el purismo y el inmovilismo de la corporación, en estos términos: 
¿Cómo puede explicarse [...] que la Academia [...] nos dé como corrientes millares de voces anticuadas, al paso que deja de admitir las que todo el mundo conoce y usa? [...] El que registre su última edición, creerá que en España no se tenía noticia en 1843 del alumbrado de gas, de los reverberos, de las prensas hidraúlicas, de los ferrocarriles, de los puentes suspendidos, ni de los barcos de vapor... (Introducción, p. VIII).

Frente al carácter normativo de la Academia, los autores de diccionarios no académicos del siglo XIX propugnan una línea basada sobre todo en el uso de las voces. En cuanto a la selección de entradas, se parte de un criterio más amplio que permite la inclusión en los diccionarios de un gran número de palabras, especialmente americanismos, voces científicas y técnicas, utilizadas por la gente de esa época, que no figuraban, sin embargo, en el repertorio académico.

Entre los diccionarios enciclopédicos del siglo XIX destacan: el Diccionario castellano de Núñez de Taboada, el Panléxico de Peñalver, el Diccionario de la lengua castellana con las correspondencias catalana y latina de Pedro Labernia, el Nuevo Diccionario de la lengua castellana de Vicente Salvá, el Diccionario nacional de Ramón Joaquín Domínguez, el Diccionario general de José Caballero y Cipriano Arnedo, el Gran diccionario de la lengua castellana de Adolfo de Castro, el Diccionario enciclopédico de la lengua española de Eduardo Chao, el Nuevo Diccionario de la lengua castellana de la Sociedad Literaria, el Novísimo Diccionario de la lengua castellana de Ramón Campuzano, El diccionario general abreviado de la lengua castellana de Lorenzo Campano, el Diccionario completo de la lengua española de Manuel Rodríguez Navas, el Diccionario enciclopédico Hispano-Americano de Montaner y Simón, y el Campano Ilustrado. Diccionario castellano enciclopédico de Manuel González de la Rosa. Este repertorio ${ }^{1}$ representa en buena parte los móviles y las características de este tipo de obras. El Campano ilustrado refleja el interés de su autor por el uso vivo y actual de la lengua. El rigor y la sistematicidad,

1 Cf. I. Anaya Revuelta (2000). 
tanto en la inclusión de voces como en el desarrollo de las definiciones, no están reñidos con la intencionalidad marcadamente práctica. Es éste el primer repertorio de lengua castellana en el que aparecen ilustraciones en color (mapas, cuadros de banderas y grabados de pesas y medidas). El carácter enciclopédico de este diccionario viene marcado además por la inclusión de nombres propios (Colón, Comte, Cortés, Cousín, Chateaubriand, etc.), así como por los desarrollos didácticos que aparecen en las voces relacionadas con las diversas ciencias:

Microbio. 'Voz debida á Pasteur y sinónima de bacilo ó de bacteria con que se designan los organismos microscópicos animales ó vegetales que se desarrollan principalmente en los líquidos; muchos de ellos son considerados como origen de varias enfermedades y su estudio es el objeto de la bacteriología'.

Lingüística. 'La ciencia del lenguaje ó estudio comparativo é histórico de las lenguas'.

El carácter "compendioso" de esta obra permite al autor consignar los principales acontecimientos de la historia universal, antigua, moderna y contemporánea, poniendo especial cuidado en lo referente a América, sus hazañas más recientes, sus héroes, artistas, etc. Su condición de Miembro de la Sociedad de Americanistas le hace buen conocedor de la realidad americana. Declara también su especial interés en no omitir ninguno de los escritores y artistas "verdaderamente célebres en el mundo entero". En lo que a la parte lingüística del diccionario se refiere, aparece una tabla de conjugación de los "verbos irregulares y defectivos, no anticuados". Los artículos lexicográficos informan de la categoría gramatical de la palabra, así como del género. El diccionario cuenta también con una lista de sinónimos, otra de abreviaturas y una "Reglas de acentuación según la reforma de la Real Academia".

En los últimos años de la década, el diccionario enciclopédico ha vuelto a cobrar importancia, y lo cierto es que bastantes casas editoriales los publican con el convencimiento de que se trata de obras de consulta muy útiles e imprescindibles para el usuario. Por otra parte, el diccionario enciclopédico presenta ciertas ventajas frente al diccionario de lengua general, y a la enciclopedia propiamente dicha. En 
primer lugar, en el diccionario enciclopédico podemos encontrar una información suficiente en lo que al significado léxico y gramatical de la palabra se refiere, y a la vez, se recogen datos sobre temas diversos pertenecientes a una cultura determinada, como por ejemplo: los Reyes Católicos, la comarca de las Hurdes, o los encajes de Camariñas. Es decir, en un diccionario enciclopédico el inventario de voces es abierto, exactamente igual que sucede con el inventario de voces de la enciclopedia. Frente a ésta, que suele ser pesada y ocupa varios volúmenes, el diccionario enciclopédico de hoy en día suele tener un tamaño adecuado para ser transportado, y lo que también ès interesante, un precio asequible, ya que las enciclopedias suelen resultar algo caras.

Fue precisamente González de la Rosa uno de los autores que propusieron el término de "enciclopedia portátil" para este tipo de diccionarios, por considerar esta denominación más exacta, ya que de hecho son obras que contienen innumerables noticias curiosas, propias de las enciclopedias. Si lo comparamos con un diccionario de lengua general, tiene la ventaja de poseer un inventario de carácter más amplio, ya que en el diccionario de lengua, en principio, no deberían aparecer ni los nombres propios ni los topónimos, cosa que, como se sabe, tampoco sucede así en la realidad. Es cierto, sin embargo, que el diccionario de lengua ofrece una información lingüística mucho más completa y exhaustiva que la que podemos encontrar en cualquiera de los diccionarios enciclopédicos. El problema está en averiguar si existen o no diccionarios lingüísticos "puros", y en delimitar, si es posible, las características que posee el género 'diccionario enciclopédico'.

\section{LOS DICCIONARIOS ENCICLOPÉDICOS ACTUALES}

\subsection{CONCEPTO Y FUNCIÓN}

Todo el mundo reconoce que existen unas obras llamadas diccionarios, otras que denominamos enciclopedias, y otras conocidas como diccionarios enciclopédicos. Como señala Gutiérrez Cuadrado (1996: 134), para comprender que son objetos diferentes, aunque muy pareci- 
dos, no hace falta tener una preparación especial. Una vez realizada la consulta en varios diccionarios del español hemos podido comprobar que el DrAE 92 no especifica "lo que es" un diccionario enciclopédico. Tampoco aparece definido en el Diccionario de términos filológicos de F. Lázaro Carreter (1977: 142) en el que se dice que existen "muchos tipos de diccionarios": diccionarios etimológicos, diccionarios históricos, diccionarios de tecnicismos, y diccionarios ideológicos, pero no aparece el diccionario enciclopédico como un tipo de diccionario diferente. En cambio sí aparece la definición de diccionario enciclopédico, en el diccionario CLAVE, en la última edición del DuE, Diccionario de uso de María Moliner (1998), y en el Diccionario del español actual (1999) de Manuel Seco. El diccionario Vox, en su edición de 1997, tanto como en las anteriores, aparece una sola entrada para enciclopedia y diccionario enciclopédico, sin hacer ninguna distinción. En la edición de 1967 del María Moliner, el diccionario enciclopédico sólo aparecía nombrado entre los diferentes tipos de diccionarios, pero no la definición. Las definiciones que proponen estos diccionarios son las siguientes:

Diccionario enciclopédico. 'El que además de las definiciones de los términos de una lengua, incluye información sobre distintas materias, personajes y lugares; enciclopedia: En un diccionario enciclopédico se incluyen nombres propios' (CLAVE, 1996).

Diccionario enciclopédico. 'Diccionario en que aparecen entradas propias de las enciclopedias, como biografías, países, etc. En los artículos, aparte de la definición del encabezamiento, suele darse una información más amplia de la materia correspondiente’ (DUE, 1998).

Enciclopedia o diccionario enciclopédico. 'El que contiene todos los conocimientos humanos en artículos ordenados alfabéticamente, o los especiales de una ciencia' (Vox 97).

Enciclopédico '[Diccionario] que abarca el conjunto de las ciencias y tiene como objetivo definir las cosas, no las palabras' (Seco, 1999).

El Diccionario Vox no distingue entre la enciclopedia y el diccionario enciclopédico, que en principio, aunque con muchas coincidencias, 
se pueden diferenciar en algunos aspectos. En cambio, para Manuel Seco, la diferencia entre un diccionario enciclopédico y un diccionario de lengua está clara: el primero define cosas, el segundo, palabras. Precisamente el Diccionario del español actual puede ser considerado como un diccionario de lengua "puro", ya que define palabras, y no incluye ni nombres propios ni topónimos.

Todo apunta a que interpretemos el diccionario enciclopédico como una obra que cabalga entre dos mundos: el diccionario de lengua y la enciclopedia. En los diccionarios enciclopédicos ya citados del siglo XIX (Peñalver, Domínguez, Núñez de Taboada, González de la Rosa, etc.), se observa como denominador común un ansia de independencia en relación a los repertorios académicos. Hay que tener en cuenta que hasta ese momento la gente asociaba la voz 'diccionario' con la de 'Academia'. El argumento principal del que se sirven estos autores es el de la superioridad de sus obras por el aumento del caudal de voces con respecto a la institución académica. Curiosamente, este mismo argumento es empleado por algunos diccionarios enciclopédicos hoy en día, como el Diccionario enciclopédico ilustrado Vox (1995), en cuyas páginas preliminares leemos que se incluyen: "Palabras de nuevo cuño que aún no han sido admitidas por la RAE, pero cuyo uso en el lenguaje está muy extendido"

En la conceptualización del diccionario enciclopédico, nos hemos servido de otras fuentes de interés, como son las obras de los lexicógrafos, y las distintas definiciones de lo que es un diccionario enciclopédico. Entre todas ellas hemos seleccionado las siguientes:

Le dictionnaire encyclopédique est un dictionnaire double. Il présente tous les caractéres du dictionnaire de langue et tous ceux de l'encyclopédie: description du lexique et description du monde (J. Rey-Debove 1971: 33).

Solución híbrida entre el diccionario de lengua y la enciclopedia, que da cabida simultáneamente al conjunto del léxico, con todas las clases de palabras, y al conjunto de las cosas, con nombres propios e ilustraciones (J. Fernández-Sevilla 1974: 67).

Es una solución híbrida entre ambas obras, pues en una enciclopedia 
tendrá cabida tanto el conjunto de las voces de una lengua, como el conjunto de cosas, hechos, lugares y personas propios de una época o cultura, esto es, un diccionario y una enciclopedia en un orden único (M. Alvar Ezquerra 1980: 116).

Entre estos dos modelos de la enciclopedia y del diccionario de la lengua, existe una obra que participa de una y otro: el diccionario enciclopédico. Es un diccionario de la lengua en virtud de la nomenclatura, que desarrolla un discurso sobre lo que designa la entrada; inserta un fragmento de descripción del mundo en el interior de la descripción de la palabra, cada vez que se presenta la ocasión. De esa manera, en el diccionario enciclopédico se tratan las palabras gramaticales de manera lingüística y los nombres de manera parcialmente enciclopédica (A. Rey 1988: 33).

Obra, efectivamente, heterogénea, que participa de las cualidades de un verdadero diccionario y de una verdadera enciclopedia (H. Hernández 1997: 160).

[Diccionario que] combina en sí mismo, en un único cuerpo, una enciclopedia de la extensión que sea con un diccionario lingüístico, generalmente monolingüe definitorio (G. Haensch 1997: 50).

Todas estas definiciones nos hablan de "diccionario doble", "solución híbrida", "obra heterogénea", es decir, la primera característica de esta obra es su carácter polivalente, ya que participa simultáneamente de las características de los diccionarios y de las enciclopedias. Se trata, pues, de una obra "más completa", ya que participa de conocimientos más amplios que los de cada una de las otras dos obras por separado. Su objetivo es dar respuesta a un mundo complejo, solventando las dudas y los problemas, de una manera rápida y eficaz.

A. Rey (1988) afirma en su definición que "en el diccionario enciclopédico se tratan las palabras gramaticales de manera lingüística y los nombres de manera parcialmente enciclopédica". Esta afirmación debería ser matizada, ya que la definición lexicográfica o nominal en un diccionario de lengua es la utilizada no sólo para definir palabras gramaticales, sino todo tipo de palabras. De hecho, es el tipo de definición más frecuente en los diccionarios de lengua. En cuanto a lo que dice de los nombres, en nuestra opinión, de acuerdo con su naturaleza, 
éstos se definen mediante un tipo de definición lexicográfica o enciclopédica, aunque, a veces, podemos encontrarnos con un tipo de definición "mixta", ya que, como hemos indicado, no siempre resulta fácil marcar el límite entre lo lingüístico y lo enciclopédico.

Siguiendo la línea de investigación iniciada por H. Hernández (1997: 161 $)^{2}$, en donde se estudiaban cuatro diccionarios enciclopédicos publicados en el año 1992, hemos seleccionado cuatro diccionarios enciclopédicos, publicados entre los años 1995 y 1998. Para agilizar la lectura, de ahora en adelante, nos referiremos a ellos mediante las siglas que siguen:

DEI: Diccionario Enciclopédico Ilustrado de VOX (1995).

DeE: Diccionario Enciclopédico Espasa, 2 vols., Espasa Calpe (1995).

GDEI: Gran Diccionario Enciclopédico Ilustrado, Grijalbo (1997).

PLI: Pequeño Larousse Ilustrado, Larousse (1998).

La norma común a todos ellos es su intención de no dar prioridad a ninguno de los dos componentes: el lingüístico y el enciclopédico. Sin embargo, se observan diferencias importantes tanto en el trato concedido a cada tipo de información, como en lo que a su presentación formal se refiere; así, por ejemplo, el Pli presenta dos partes separadas por unas hojas de color rosa, una que corresponde a la parte lingüística, y otra que corresponde a la parte enciclopédica. En cualquier caso, creemos que este género denominado diccionario enciclopédico, que por su propia naturaleza debe comprender todo el léxico de una lengua y el conocimiento cultural de una sociedad determinada, y que, además debe ajustarse a unas dimensiones que lo hagan de fácil manejo, ni puede ser completo ni puede ser preciso, tanto en lo que se refiere al

2 Humberto Hernández ha estudiado las características de algunos diccionarios enciclopédicos del siglo XX: Diccionario enciclopédico Santillana (DES), Gran Diccionario Salvat (GDS), Diccionario enciclopédico ilustrado (DEI), Parramón. Diccionario enciclopédico (PDE), y Larousse. Diccionario enciclopédico, (LDE), todos ellos publicados en 1992, aunque nuevos son sólo los tres primeros, ya que los dos últimos son ediciones revisadas y actualizadas de versiones anteriores. 
plano lingüístico, como al enciclopédico. En el estudio que hemos realizado se han barajado los siguientes parámetros:

1. $\mathrm{N}^{\mathrm{o}}$ de entradas $\mathrm{y}^{\circ}$ de ilustraciones.

2. Macroestructura y lematización del diccionario.

3. Marcas de uso, información gramatical, colocaciones, etc., ("Primer enunciado" de la definición) ${ }^{3}$.

4. La definición propiamente dicha ("Segundo enunciado de la definición").

5. Características generales del repertorio.

6. Relación con las 40 primeras palabras del DRAE 92 ( $a$ / abalaustrado).

Tanto en el DEI, como en el GDEI y en el PLI aparece el término ilustrado en el título, lo cual no deja de ser una redundancia, ya que los diccionarios enciclopédicos se caracterizan, entre otras cosas, por llevar ilustraciones. En los cuatro diccionarios se ha incorporado el orden alfabético internacional, es decir, los dígrafos ch y ll aparecen dentro de las letras c y 1 respectivamente; este dato significa un avance con respecto a los datos recabados por H. Hernández (1997), puesto que de los diccionarios anteriormente citados del año 1992, sólo el DES y el GDS incorporaban el orden alfabético internacional, mientras que el DEI, el PDE y el LDE mantenían el orden acostumbrado. El número de artículos oscila entre los 72.000 del DeE y los más de 100.000 del GDEI; el número de ilustraciones va de las 3.500 del DEI a las 8.000 que presentan el DEE y el GDEI. En los prólogos de los cuatro repertorios se declaran las mismas intenciones y las mismas características: obra actualizada, didáctica, equilibrada, sintética, clara y completa.

- El DeI presenta la particularidad de ser, junto con el GDEI, el único que presenta el nombre científico en las voces referidas a plantas y a animales. La supresión de las equivalencias latinas es una tradición que tuvo lugar no sólo en la lexicografía española, sino también en la europea, como símbolo de una progresiva deslatinización de la cultura

3 La terminología corresponde a Manuel Seco (1987: 16-22). 
occidental. El humanista Rufino José Cuervo reclamó, sin embargo, la equivalencia latina en aquellas voces pertenecientes al campo de las ciencias naturales, es decir, los nombres científicos establecidos por los naturalistas a partir de Linneo, a pesar de lo cual la Real Academia no ha incluido hasta ahora el nombre científico en ninguno de los nombres de plantas y de animales. Por otra parte, sabemos que algunos autores del siglo XVIII (Antonio de Alcedo, Ignacio de Asso ${ }^{4}$ ), preocupados por esta cuestión, presentaron en sus obras el término científico junto al nombre vernáculo en los diccionarios. Este diccionario registra 17 artículos de los primeros 40 que aparecen en el DraE 92. Desde un punto de vista formal, en los casos de palabras homónimas, las minúsculas se anteponen a las mayúsculas. Por ejemplo:

terciario. 'sector productivo'

Terciario. 'Era geológica'

- El DeE comprende dos volúmenes de pequeño tamaño. Es el único con ilustraciones en blanco y negro, ya que los demás diccionarios analizados presentan las ilustraciones a todo color. Se han incorporado neologismos, tecnicismos y extranjerismos, así como voces de uso restringido (localismos, arcaísmos y voces desusadas), voces éstas que se han eliminado en los otros diccionarios por economía. Aparecen los sinónimos y las localizaciones geográficas, pero se han eliminado las etimologías. Registra 16 voces de las 40 primeras del DrAE 92.

- El GDEI es el único de los diccionarios estudiados que presenta las fuentes de información, ya que incorpora una lista de colaboradores en los distintos campos del saber (Arte, Ciencias naturales, Derecho, etc.), que son los que han redactado los artículos; según se nos informa en las páginas preliminares, no se trata de una traducción ni de una adaptación, aunque se reconoce haber tenido en cuenta el Diccionario de la Lengua Española, el Diccionario Histórico de la Lengua Española y El Diccionario Manual e Ilustrado de la RAE. En el prólogo, redactado por Borges, se manifiesta el interés por abarcar el lenguaje de Espa-

4 Cf. I. Anaya Revuelta (1998). 
ña y de Hispanoamérica. Este diccionario incorpora el nombre científico a las definiciones de nombres de plantas y animales. La aparición de las etimologías queda restringida a los casos de: voces homónimas de distinta procedencia: Abalear 1 (de baleo) y Abalear 2 (de bala), voces raras y curiosas, y neologismos que no pertenecen al cuerpo patrimonial del idioma.

En las ilustraciones no se sigue ningún modelo en concreto, sino que se seleccionan las palabras que deben ir ilustradas, con la idea de ampliar y completar los textos. De los 40 primeros artículos del DRAE, el GDEI registra 24 voces.

- El PLI, como hemos señalado, distingue dos partes bien diferenciadas: Lengua española y Cultura general. Dentro de la parte correspondiente a la lengua española se incluyen definiciones lingüísticas con la información enciclopédica que se considera necesaria en cada caso. En la parte denominada cultura general se sitúa la información correspondiente a geografía, literatura, arte, ciencia, y técnica. Las ocho páginas de color rosa que sirven para separar las dos partes recogen una serie de refranes y frases hechas. A la primera sección (pp. 25-1056), le corresponden los términos comunes, y a la segunda sección (pp. 10731758), los nombres propios. Los cambios de categoría gramatical aparecen señalados con el símbolo $\$$. La etimología sólo aparece "cuando se considera que es relevante". Desde nuestro punto de vista, la etimología de una palabra siempre es relevante en un diccionario; otra cosa distinta es que, a veces, no aparezca la etimología porque no se conozca, como sucede con muchas palabras en el DrAE. Menéndez Pidal, en el "Prólogo al diccionario que deseamos" argumenta de esta manera la importancia de la etimología en los diccionarios:

La etimología no es una curiosidad erudita de interés puramente histórico, sino que es la base misma de la propiedad idiomática. Sólo cuando conocemos el origen de un vocablo podemos comprender el fundamento y límites de su fuerza expresiva.

En cualquier caso, el número de voces en que aparece la etimología en el Pli es muy reducido. Se incluyen algunos plurales considerados irregulares, como por ejemplo: galop 'danza de origen húngaro' plural: 
galops. A pesar de la diferenciación de las dos partes, la lingüística y la enciclopédica, en algunas definiciones comprendidas en la parte "lingüística", aparecen explicaciones enciclopédicas, precedidas en este caso del signo ã. Las locuciones y formas compuestas de la voz van precedidas del signo $\square$. La información taxonómica en los nombres referidos a plantas y a animales aparece entre paréntesis y en letra cursiva. Hemos tomado como referencia el artículo correspondiente a la palabra abeja, y lo hemos comparado con la información que aparece en el DRAE 92. En el Diccionario académico encontramos:

\begin{abstract}
abeja. (Del lat. apicǔla.) f. Insecto himenóptero, de unos 15 milímetros de largo, de color pardo negruzco y con vello rojizo. Vive en colonias, cada una de las cuales consta de una sola hembra fecunda, muchos machos y numerosisimas hembras estériles; habita en los huecos de los árboles o de las peñas, o en las colmenas que el hombre le prepara, y produce la cera y la miel. \| 2. fig. Persona laboriosa y previsora. \| albanila. Insecto himenóptero que vive apareado y hace para su morada agujeros horizontales en las tapias y en los terrenos duros. \| carpintera. Himenóptero del tamaño y forma del abejorro, y de color negro morado; fabrica su panal en los troncos secos de los árboles, y de aquí su nombre. Es común en España. \| machiega. abeja neutra u obrera. I maesa o maestra. Hembra fecunda de las abejas, única en cada colmena. \| neutra u obrera. Cada una de las que carecen de la facultad de procrear y producen la cera y la miel. \| reina. abeja maesa o maestra. II muerta es la abeja que daba la miel y la cera. fr. p. us. con que se indica haber muerto la persona que atendía a todas nuestras necesidades.
\end{abstract}

Por otra parte, el PLI define la abeja de este modo: 
ABEJA n. f. (lat apiculam). Insecto social que se cria en colmenas y produce miel y cera. (Orden himenópteros.) 2. Fig. Persona laboriosa. - Nido de abeja (BORD.), punto de adomo que se hace en una tela fruncida.

- El horribre cría abejas por los productos que le proporcionan: la miel y la cera (apicúttura). Las abejas se agrupăn en colonias o colmerias. En cada colmena existe una sola hembra fértil, la reina, que es fecundada por un solo macho, el zángano, en cada vuelo nupcial. La mayoría de las abejas, llamadas obreras, son estériles y su misión es recolectar el polen y el néctar de las fiores con el que elaboran la miel, alimento de las larvas, y la cera con la que construyen el panal, formado por alvéolos o celdillas hexagonales en donde la reina deposita los huevos. También son las encargadas de las tareas de vigilancia y nutrición de las recién nacidas o de limpieza de la colmena las abejas obreras poseen un lenguaje (danza) mediante el cual informan a las demás de la posición y la distancia de la fuente de alimento.
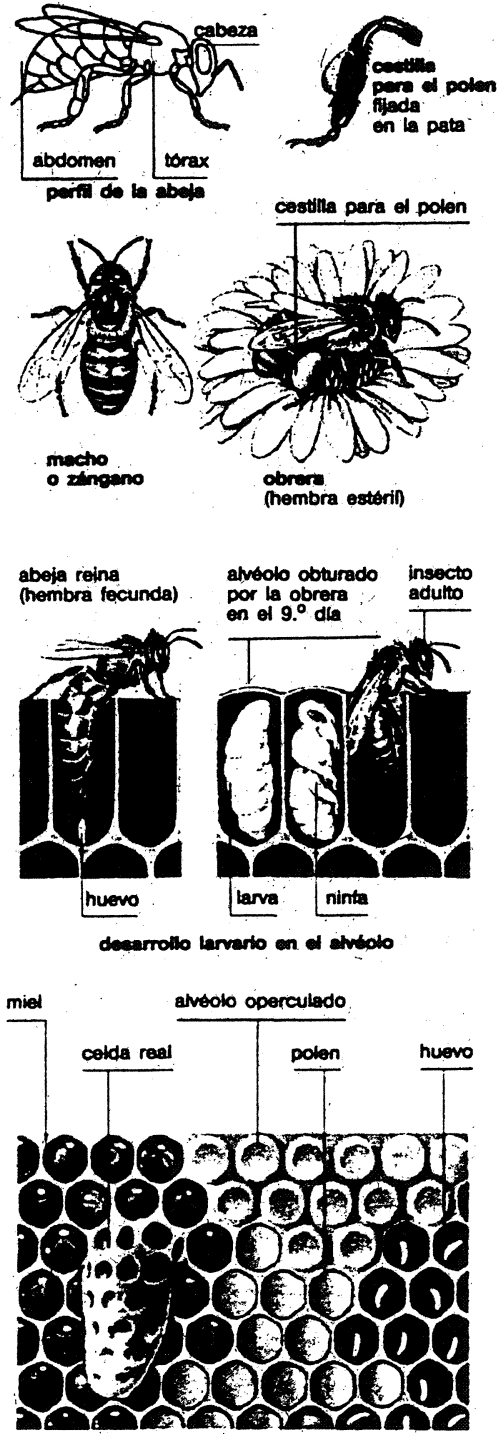

abeja

socibn de un pand

En el artículo del DRAE 92 podemos distinguir seis partes bien diferenciadas: 
1. Etimología.

2. Información gramatical: género (f).

3. Definición enciclopédica, en donde las informaciones siguen un orden determinado, que coincide, por ejemplo, con muchas de las definiciones de los peces ${ }^{5}$ : orden, tamaño, color, aspecto físico general, hábitat y función.

4. Sentido figurado de la palabra: "persona laboriosa y previsora".

5. Enumeración y explicación de las clases de abejas que existen (información enciclopédica): albañila, carpintera, machiega, neutra u obrera y maesa o maestra.

6. Fraseología. Aparece una expresión fija "muerta es la abeja que daba la miel y la cera", que significa que ha muerto la persona que atendía todas nuestras necesidades.

Es decir, tanto la tercera parte como la quinta en el DRAE 92 son de carácter enciclopédico. Por su parte, el Pli nos da la siguiente información:

1. Información gramatical: categoría (n), y género (f).

2. Etimología.

3. Definición lexicográfica de la abeja: "Insecto social que se cría en colmenas y produce miel y cera", con el orden al cual pertenece la abeja (Orden himenópteros), entre paréntesis. Estamos ante una definición lexicográfica donde la palabra se define mediante el género próximo (insecto social) y la diferencia específica (que se cría en colmenas...).

4. Sentido figurado: "persona laboriosa".

5. Fraseología. Nido de abeja: "punto de adorno que se hace en una tela fruncida".

6. Desarrollo enciclopédico. Precedida del signo $\square$, aparecen una serie de datos de carácter enciclopédico, como la forma de vida de las abejas, su lenguaje, etc. Se resaltan en cursiva una serie de pala-

5 Cf. I. Anaya Revuelta (1999). 
bras que forman parte del campo semántico de la abeja: apicultura, zángano, obreras, panal, etc.

Es decir, la definición de abeja que aparece en el DRAE 92 es una definición enciclopédica, y en cambio, la definición que nos da el PLi para esta misma palabra es una definición lexicográfica, ya que se puede descomponer en semas: 'insecto', 'vive en colmenas', 'produce miel', etc. Por otra parte, el PLI nos da más información gramatical (categoría y género), que la que aparece en el DrAE 92 (sólo el género). Los dos diccionarios coinciden en dar información etimológica y una entrada destinada a la fraseología, aunque referida a diferentes frases.

De la comparación de estos dos artículos resulta un análisis interesante que nos va a permitir obtener alguna conclusión. En el PLI se ha optado por separar ambas informaciones, mientras que en el DRAE 92 no se hace tal distinción. Además, la información enciclopédica que se añade en el PLI se centra casi exclusivamente en la vida y en la organización de las abejas. Es probable que un zoólogo considere que la información sobre diferentes clases de abejas que nos da el DRAE en la segunda acepción es la fundamental, de lo cual no dice nada el PLI. Es decir, al menos en lo que respecta a las definiciones de ciertas clases de palabras, no siempre podemos trazar una línea divisoria clara entre el diccionario de lengua y el diccionario enciclopédico.

Otra característica importante que permite establecer alguna diferencia es que los diccionarios enciclopédicos, al igual que sucede con las enciclopedias, tienen que estar actualizados. Esto mismo sucede con los diccionarios de lengua, pero en este sentido, los diccionarios de lengua, generalmente, tardan más tiempo en ser revisados. Pensemos, por ejemplo, que el DRAE 92 tardó ocho años en aparecer desde su última edición de 1984; el DuE, por otros motivos, ha tardado 31 años en ser revisado; en cambio, el PLI, desde su primera edición de Claude Auger en París (1912), cuya redacción corrió a cargo de Miguel de Toro y Gisbert, ha sido editado en varias ocasiones. La anterior fue dirigida por $\mathrm{M}^{\mathrm{a}}$ José Sarto, y, aunque en la portada lleva la fecha de 1997, se publicó en 1996; de la misma manera, esta nueva edición que ahora comentamos, lleva en su portada la fecha de 1999, aunque fue publica- 
da en 1998. Este diccionario registra 22 artículos de los primeros 40 que aparecen en el DRAE.

$\mathrm{Al}$ igual que el GDEI, el PLI incurre en el error de lematizar todas las entradas con mayúsculas, lo cual dificulta no sólo el reconocimiento de los nombres propios y topónimos, sino también, la percepción de acentos y diéresis.

Los datos del estudio comparativo realizado entre los cuatro diccionarios se pueden resumir en el cuadro siguiente:

\begin{tabular}{|c|c|c|c|}
\hline & $\begin{array}{c}\text { Macroestructura } \\
\text { Lematización }\end{array}$ & $\begin{array}{c}\text { Informaciones } \\
\text { varias } \\
\left(1^{\mathrm{er}} \text { enunciado }\right)\end{array}$ & $\begin{array}{c}\text { Naturaleza } \\
\text { de la definición } \\
\left(2^{\circ} \text { enunciado }\right)\end{array}$ \\
\hline DEI & $\begin{array}{l}80.000 \text { artículos } \\
3.000 \text { fotografías a color y } 500 \\
\text { cuadros. } \\
\text { En las voces homónimas, las } \\
\text { minúsculas se anteponen a las } \\
\text { mayúsculas. } \\
\text { Se incluyen términos no reco- } \\
\text { gidos por la RAE, de uso ex- } \\
\text { tendido. } \\
\text { Empleo de las mayúsculas só- } \\
\text { lo para la } 1^{\text {a }} \text { letra de los n. pro- } \\
\text { pios. }\end{array}$ & $\begin{array}{l}\text { Información gra- } \\
\text { matical. } \\
\text { Locuciones. } \\
\text { Marcas de ámbi- } \\
\text { to. } \\
\text { El nombre cientí- } \\
\text { fico al final, en } \\
\text { cursiva y entre } \\
\text { paréntesis. }\end{array}$ & $\begin{array}{l}\text { Definiciones lexi- } \\
\text { cográficas. } \\
\text { Definiciones en- } \\
\text { ciclopédicas. }\end{array}$ \\
\hline DEE & $\begin{array}{l}72.000 \text { artículos ( } 12.500 \text { bio- } \\
\text { grafias). } \\
8.000 \text { ilustraciones. } \\
\text { Presentación en dos volúme- } \\
\text { nes. } \\
\text { Se incluyen voces de uso res- } \\
\text { tringido (localismos, arcaís- } \\
\text { mos, voces en desuso). Las } \\
\text { mayúsculas se emplean sólo } \\
\text { para la } 1^{\mathrm{a}} \text { letra de los n. pro- } \\
\text { pios. }\end{array}$ & $\begin{array}{l}\text { Información gra- } \\
\text { matical. } \\
\text { No aparecen eti- } \\
\text { mologías. } \\
\text { No aparecen mar- } \\
\text { cas de ámbito. } \\
\text { No figuran las lo- } \\
\text { calizaciones geo- } \\
\text { gráficas. }\end{array}$ & $\begin{array}{l}\text { Definiciones lexi- } \\
\text { cográficas (mu- } \\
\text { chas de ellas si- } \\
\text { nonímicas). } \\
\text { Definiciones en- } \\
\text { ciclopédicas. }\end{array}$ \\
\hline
\end{tabular}




\begin{tabular}{|c|c|c|c|}
\hline & $\begin{array}{c}\text { Macroestructura } \\
\text { Lematización }\end{array}$ & $\begin{array}{c}\text { Informaciones } \\
\text { varias } \\
\left(1^{\mathrm{er}} \text { enunciado }\right)\end{array}$ & $\begin{array}{c}\text { Naturaleza } \\
\text { de la definición } \\
\left(2^{\circ} \text { enunciado) }\right.\end{array}$ \\
\hline GDEI & $\begin{array}{l}100.000 \text { artículos. } \\
8.000 \text { ilustraciones. } \\
\text { Léxico general, con especial } \\
\text { atención a los americanismos. } \\
\text { Mayúscula y negrita para to- } \\
\text { das las entradas. } \\
\text { Minúscula negrita para la } 2^{\mathrm{a}} \\
\text { acepción. } \\
\text { Aparecen siglas (sin puntos). }\end{array}$ & $\begin{array}{l}\text { Información gra- } \\
\text { matical. } \\
\text { Inversiones se- } \\
\text { mánticas. } \\
\text { Etimologías (en } \\
\text { el caso de voces } \\
\text { homónimas de } \\
\text { distinta proceden- } \\
\text { cia). } \\
\text { El nombre cientí- } \\
\text { fico aparece de- } \\
\text { trás del lema, en- } \\
\text { tre paréntesis. }\end{array}$ & $\begin{array}{l}\text { La información } \\
\text { léxicográfica apa- } \\
\text { rece mezclada } \\
\text { con la enciclopé- } \\
\text { dica; si ésta es } \\
\text { muy extensa apa- } \\
\text { rece aparte. }\end{array}$ \\
\hline PLI & $\begin{array}{l}84.000 \text { artículos. } \\
4.750 \text { ilustraciones. } \\
\text { Lematización en mayúsculas. } \\
\text { Organización del contenido en } \\
\text { dos partes bien diferenciadas. } \\
\text { Marcas de ámbito y de uso. } \\
\text { Gran } n^{\circ} \text { de americanismos. } \\
\text { Clasificación taxonómica en } \\
\text { los n. zoológicos. }\end{array}$ & $\begin{array}{l}\text { Información gra- } \\
\text { matical. } \\
\text { Etimología (cuan- } \\
\text { do es relevante). } \\
\text { No aparecen n. } \\
\text { científicos. } \\
\text { Aparecen: plura- } \\
\text { les irregulares, } \\
\text { marcas de mate- } \\
\text { ria, locuciones y } \\
\text { formas compues- } \\
\text { tas. }\end{array}$ & $\begin{array}{l}\text { Definiciones lexi- } \\
\text { cográficas. } \\
\text { Explicaciones en- } \\
\text { ciclopédicas se- } \\
\text { paradas por una } \\
\text { marca. }\end{array}$ \\
\hline
\end{tabular}

En el cuadro se hace referencia de manera muy escueta al tipo de definición que aparece en estos diccionarios. En el DEI y en el DEE aparecen definiciones lexicográficas y definiciones enciclopédicas diferenciadas en función de la palabra que se define; en cambio, en el GDEI, cuando la información enciclopédica se considera muy extensa, se añade aparte. Esto mismo sucede en el PLI, donde la información enciclopédica queda desvinculada de la definición lexicográfica por 
una marca específica ( $\square$ ). Desde nuestro punto de vista, la cantidad de información enciclopédica en un diccionario, es decir el número de definiciones enciclopédicas, es un dato fundamental para su caracterización. Con la aparición de diccionarios de lengua en los que aparecen ilustraciones, como es el caso de los diccionarios ilustrados de lengua Vox, unida a la creciente información enciclopédica de nuestros diccionarios, resulta difícil establecer una barrera infranqueable entre un tipo de diccionarios y otro. Por otra parte, es indudable que el diccionario de lengua Vox dedica más atención al aspecto lexicográfico que cualquiera de los diccionarios enciclopédicos aquí comentados.

\subsection{CARACTERÍSTICAS DEL DICCIONARIO ENCICLOPÉDICO}

De todo ello se deduce que las claves para reconocer un diccionario enciclopédico actual son las siguientes:

1. Criterio seguido para la selección de voces. Intención acumulativa y afán de totalidad por comprender toda la ciencia y el saber. Inclusión de un gran número de voces científico-técnicas y de americanismos.

2. Inclusión de nombres propios y de topónimos.

3. Ordenación alfabética de materias, tomada de los diccionarios de lengua, y no por temas, como sucedía en la Antigüedad y en la Edad Media, y como ocurre en algunas enciclopedias y en algunos tipos de diccionarios (diccionarios ideológicos). En ocasiones, como sucede con el PLI, además del orden alfabético, se establece una diferencia física entre la parte enciclopédica y la parte lingüística, separándolas por alguna marca, en este caso, por ocho hojas de color rosa.

4. Aparición de ilustraciones.

5. Es un diccionario de fácil uso y manejo, a diferencia de lo que sucede, por ejemplo, con las enciclopedias.

6. Información clara y sintetizada, ya que su extensión limitada así lo exige. La capacidad de síntesis de un diccionario enciclopédico es uno de los parámetros que permiten determinar la calidad del mismo. 
7. Datos actualizados y correctos. Es importante que el usuario encuentre actualizada la información que precisa. Por ejemplo, en la parte enciclopédica del PLI encontramos la siguiente información:

Alarcos Llorach. '(Emilio), lingüista español (Salamanca 1922Oviedo 1998). Introdujo en España la fonología y el estructuralismo (Fonología española, 1950). [Real Academia 1973].

8. En función de la naturaleza de lo definido, predominio de la información enciclopédica, para lo cual es imprescindible la opinión de un grupo de personas con un alto grado de especialización.

9. En cuanto al tipo de definición que predomina en esta clase de diccionarios, ésta viene determinada, en cierta medida, por la naturaleza misma de las voces. Cada clase de palabras exige una modalidad de definición. En los diccionarios enciclopédicos la definición enciclopédica es la más frecuente. Algunas voces pueden ser definidas desde un punto de vista lingüístico, y otras, en cambio, sólo pueden ser definidas mediante una explicación de tipo enciclopédico. En un estudio realizado sobre la definición enciclopédica ${ }^{6}$ se señalan las características de este tipo de definición, que, desde nuestro punto de vista, se pueden resumir de esta manera:

9.1. Carácter científico o divulgativo, según los conocimientos que se tengan de la realidad, el metalenguaje empleado, y el destinatario de la definición. De acuerdo con estos tres parámetros hemos distinguido dos tipos de definiciones enciclopédicas:

a) La definición científica que utiliza para la descripción del ser u objeto una terminología específica de una ciencia determinada. Generalmente estas definiciones combinan en su enunciado los términos científicos con los términos vulgares. Por ejemplo la definición de abadejo tomada del GDEI:

Abadejo. 'Pez gadiforme, de la familia de los Gádidos. Mide $1 \mathrm{~m}$. sin barbillón, abunda en aguas frías del hemisferio Norte; comestible, es sujeto de activa pesca'. 
Debido posiblemente al principio de economía, las definiciones, a veces, como en este caso, son descuidadas en el aspecto lingüístico.

b) La definición divulgativa, que pone al alcance de cualquier hablante de una lengua el significado de un ser u objeto de la realidad, de manera comprensible, es decir, no puede aparecer en la definición ningún término que forme parte de un conocimiento especializado ${ }^{7}$. Por ejemplo, la definición que da el Pli para la palabra anteojo:

Anteojo. 'Instrumento óptico formado por un sistema de lentes adecuadamente dispuestas en el interior de un tubo, con el que se obtienen imágenes aumentadas de objetos lejanos'

Generalmente los diccionarios enciclopédicos combinan los dos tipos de definición citados, según la naturaleza del definido.

9.2. Por la forma en que están expresadas, las definiciones enciclopédicas pueden ser definiciones propias $^{8}$, formuladas en metalengua del contenido:

analgesia: 'Abolición de la sensibilidad al dolor'

analfabeto: 'Que no sabe leer ni escribir'

y definiciones impropias, las que están formuladas en metalengua del signo:

anciano: 'Dícese de la persona que tiene muchos años'

anclaje: 'Acción de anclar'

Como es sabido, las definiciones propias admiten el 'principio de sustituibilidad', mientras que las definiciones impropias no lo admiten. También es importante, en este sentido, la cantidad y el orden en

7 Cf. A. Wierzbicka (1985) afirma que en la definición de una palabra como tigre no debe aparecer ningún conocimiento que forme sólo parte del conocimiento de un especialista.

8 Cf. Seco (1987: 22). 
que figura la información enciclopédica. En función de la cantidad de información enciclopédica que presentan, algunas son definiciones impropias pues no admiten 'el principio de sustituibilidad', mientras que otras sí lo admiten. En el GDEI la información enciclopédica, cuando es extensa aparece aparte; en este caso, la definición no admite el 'principio de sustituibilidad'. Lo mismo sucede en las explicaciones enciclopédicas de las definiciones del PLI. Por otra parte, las definiciones sinonímicas, o más exactamente, las que siguen el esquema de las "equivalencias', sí admiten la sustituibilidad, y son, por lo tanto, definiciones propias. En todas ellas se cumple el "principio de equivalencia categorial", es decir, la identidad de categoría entre definiendum y definiens ${ }^{10}$. Por ejemplo, en el Pli encontramos los siguientes ejemplos:

Lagotería. 'Zalamería'

Laja. 'Lancha, piedra lisa'

Lamber. 'Lamer'

Lambrija. 'Lombriz'

9.3. Las definiciones enciclopédicas tienen una finalidad didáctica evidente: informar y enseñar al usuario algo que desconoce. El grado de información está directamente relacionado con el carácter científico o divulgativo de la definición. Prevalece la información sobre el dato factual.

9.4. Suelen ser algo extensas. No se trata de dar toda la información existente sobre el definiendum, característica ésta más propia de las enciclopedias, sino de dar la información exacta y completa, a partir de la cual el usuario pueda proseguir en otras búsquedas más específicas. En este sentido, hay que distinguir entre lo que podríamos lla-

9 Cf. C. Castillo Peña (1992) e I. Anaya (1999).

10 Sobre este aspecto son interesantes las aportaciones de L. Zgusta (1971:258), J. Rey-Debove (1971: 203), B. Quemada (1968: 460) y J. A. Porto Dapena (1980: $304)$, entre otros autores. 
mar la información adicional necesaria y la información hiperespecífica que no supone ningún avance para el conocimiento, sino todo lo contrario.

9.5. En lo que a la sintaxis se refiere, para este tipo de definiciones, y de manera especial para aquellas que pertenecen al ámbito de la zoología o de la botánica, no es suficiente un sintagma definitorio y necesariamente tienen que aparecer varios sintagmas, tantos como sean necesarios para que la definición resulte completa. Manuel Seco (1987:30-31) habla de "ruptura" de la unidad sintáctica, necesaria para la definición lexicográfica propiamente dicha. Estos "desarrollos sintácticos secundarios" no se producen con cualquier tipo de nombre, sino sólo en los nombres propios, y en los pertenecientes a un ámbito particular (Arte, Filosofía, Química, Hípica, etc.).

9.6. En cuanto al metalenguaje, las definiciones enciclopédicas pueden ser de dos tipos: perifrásticas y sinonimicas. El metalenguaje empleado debe ser claro, preciso, actual y sencillo; es decir, no deben aparecer voces anticuadas o en desuso. En las definiciones de los diccionarios enciclopédicos encontramos los mismos "defectos" que en cualquier diccionario de lengua, como es por ejemplo la circularidad. Veamos un ejemplo tomado del PLI:

Denotador. 'Artificio o parte de una munición que sirve para provocar la denotación de un explosivo"

Denotación. “Acción y efecto de denotar'

9.7. Deben ser objetivas, ya que se trata de explicitar los conocimientos que se tienen de la realidad, sin ningún rasgo de subjetividad. No deben aparecer rasgos que reflejen la ideología del autor. Un diccionario debe ser tolerante y respetuoso con todas las ideologías. El lexicógrafo no puede dejarse influir por su forma particular de ver la vida, y como afirman J. A. Pascual y M.C. Olaguibel (1991: 74), debe intentar situarse en una posición intermedia entre todos los hablantes, si bien es cierto que rara vez se consigue, ya que cada entrada del diccionario implica la actitud del lexicógrafo ante una determinada realidad política, religiosa, moral, etc. Si comparamos las primeras acep- 
ciones de la palabra católico en el DRAE 92 y en el PLi se observa la diferente interpretación en cada uno de los diccionarios:

Católico. 'adj. universal, que comprende y es común a todos; y por esta calidad se ha dado este nombre a la Iglesia Romana' (DRAE 92).

Católico. 'Relativo al catolicismo; que profesa el catolicismo. 2. Dícese de la Iglesia cristiana que reconoce el magisterio supremo del papa, obispo de Roma. 3. Universal, que se extiende a todo el mundo' (PLI)

Es decir, en el DRAE 92, se da por supuesto que la Iglesia católica es la común a todos, mientras que en el PLI se da la información de manera más objetiva.

9.8. Las definiciones enciclopédicas están sujetas al cambio, ya que dependen del grado de conocimiento que se tenga de la realidad. En cambio, si una definición lexicográfica cambia es porque cambia la estructura de la lengua, lo cual es mucho más difícil. El conocimiento científico evoluciona con el tiempo, y este hecho repercute directamente en el cambio de la definición enciclopédica. Es muy importante que estas definiciones presenten la información actualizada y que, en la medida de lo posible, se citen las fuentes de donde procede la información. De los diccionarios analizados hemos visto que sólo el GDEI nos facilita las fuentes de información.

9.9. Muchas de las definiciones enciclopédicas van acompañadas de ilustraciones que proporcionan la información con mayor facilidad y rapidez que las descripciones. Cualquier tipo de imagen, dibujo, fotografía, etc., es un instrumento de apoyo muy útil para este tipo de definición.

\section{CONCLUSIÓN}

El diccionario enciclopédico es un instrumento polivalente que comprende en sí mismo parte de la información de una enciclopedia y parte de la información de un diccionario general de lengua. La distinción entre definir palabras y describir objetos se confunde a veces en este tipo de obras de carácter híbrido. 
No todos los diccionarios enciclopédicos cuidan en la misma medida la información lingüística, pero hoy en día se exige cada vez más que estos diccionarios faciliten, además de las informaciones gramaticales básicas, otro tipo de informaciones como sinónimos y antónimos, sintagmas lexicalizados, niveles de estilo, etc. Es un hecho evidente que la lexicografía en nuestros días no limita su actividad al plano del contenido, ni siquiera en estos diccionarios que aquí hemos denominado lingüísticos "puros", ya que cada vez se hace más hincapié en el estudio de la función de las palabras. Este planteamiento nos lleva a otra reflexión más general y que se escapa del propósito de este trabajo: la necesidad de estudiar de forma conjunta las relaciones que existen entre léxico y gramática.

La cuestión que aquí nos interesa es saber si podemos reconocer el diccionario enciclopédico como un diccionario diferente del diccionario lingüístico "puro" y como una obra distinta de la enciclopedia. En teoría las diferencias parecen claras y todo el mundo sabe distinguir estas obras. Sin embargo, en la práctica, los límites entre un tipo de obras y otro suelen resultar algo confusos. Por ejemplo, ¿qué número de voces científicas debe incluir un diccionario de lengua para seguir siendo 'lingüístico' y no pasar a pertenecer al grupo de los denominados 'enciclopédicos'? Es evidente que muchos términos que pertenecen a las diferentes ciencias y técnicas han sido incluidos en los diccionarios de lengua por necesidad. Pensemos en el Diccionario del español actual de Seco (1999), que en principio puede ser considerado como prototipo de lo que es un diccionario lingüístico, y sin embargo, son muy numerosos los términos correspondientes al conjunto de las ciencias que aparecen en este diccionario. Por ejemplo, en este diccionario aparecen cuatro términos referidos a la Química: metanífero, metano, metanoico y metano, mientras que el DRAE 92 sólo recoge de estos cuatro, el de metano. En cambio, el nombre de María aparece definido en el DrAE 92 como nombre propio ("nombre de la Madre de Jesús"), mientras que el diccionario de Seco recoge los sigientes significados: 1. "galleta redonda"; 2. "ama de casa"; 3. "asignatura del grupo constituido por Religión, Gimnasia y Formación del Espíritu Nacional"; 4. "marihuana", etc. En el Diccionario Ilustrado de la Lengua Española de Vox 
(1997), otro ejemplo de diccionario lingüístico, aparecen no sólo muchos de estos términos, sino también ilustraciones y cuadros temáticos similares a los que encontramos en cualquier enciclopedia.

En definitiva, el carácter enciclopédico de un diccionario viene dado, en nuestra opinión, por ese carácter de mezcla entre el diccionario lingüístico y la enciclopedia, ya que reúne características propias de los dos tipos de obras. Por otra parte, un diccionario de lengua contiene más o menos información enciclopédica, en función del número de definiciones enciclopédicas que contenga. La información enciclopédica en los diccionarios lingüísticos no debe ser interpretada, creemos, como algo negativo, ya que, el diccionario, instrumento útil que todos manejamos, actúa como el máximo transmisor de los conocimientos.

\section{BIBLIOGRAFÍA}

Alvar EzQuerra, Manuel. (1980): “¿Qué es un Diccionario?”, Lingüística Española Actual, II, 1, pp. 103-118.

ANAYA REVUelTA, Inmaculada. (1998): "La Ictionimia en la obra de don Ignacio de Asso", Archivo de Filología Aragonesa, LIV-LV, pp. 141-179.

- (1999): La definición enciclopédica. Estudio del léxico ictionímico, Colección Biblioteca de Filología Hispánica, Madrid, CSIC.

_ (2000): "Una nota para la Historia de la Lexicografía española: El Campano ilustrado. Diccionario castellano enciclopédico de Manuel González de la Rosa (1898)", en Actas del II Congreso Inter-

- nacional de Historiografia Lingüística, Universidad de León.

_ (en prensa): "Sobre el carácter enciclopédico de los diccionarios del español".

AZORÍN FERNÁNDEZ, Dolores (1994-1995): "De la teoría a la práctica lexicográfica: El nuevo diccionario de la lengua castellana de Vicente Salvá", Estudios de Lingüística, 10, pp. 9-20.

—_ (1996-1997): "La lexicografía española en el siglo XIX”, Estudios de Lingüística, 11, pp. 11-122.

Castillo PeÑA, Carmen (1992): "La definición sinonímica y los círculos viciosos", Boletín de la Real Academia Española, t. LXXII, cuaderno CCLVII, pp. 463-566. 
Clave, DicCionario de uso del español aCtUal (1996), Madrid, S. M.

COVARruBias, Sebastián de (1611): Tesoro de la lengua castellana o española, Madrid, Luis Sánchez, ed. de Martín de Riquer, 1492. Edición facsímil, Madrid, 1971.

DICCIONARIO ENCICLOPÉDICO ESPASA (1995), 2 vols., Madrid, Espasa Calpe. DiCCIONARIO ENCICLOPÉDICO ILUSTRADO VOX (1995), Barcelona, Bibliograf.

DICCIONARIO GENERAL ILUSTRADO DE LA LENGUA ESPAÑOLA VOX (1997), ed. de M. Alvar Ezquerra, Barcelona, Bibliograf.

FernÁNDEz SEvilla, Julio (1974): Problemas de Lexicografia actual, Bogotá, Instituto Caro y Cuervo.

GonZÁleZ DE la Rosa, Manuel (1891): Campano illustrado. Diccionario castellano enciclopédico, París, Garnier Hermanos.

GRAN ENCICLOPEDIA LAROUSSE (1993), Barcelona, Planeta.

GRAN DICCIONARIO ENCICLOPÉDICO ILUSTRADO (1997), Barcelona, Grijalbo.

GutiÉRREZ CUADRADO, Juan (1996): "Enciclopedia y diccionario", en E. Forgas, coor., Léxico y diccionarios, Tarragona, Universitat Rovira i Virgili, pp. 133-159.

HERNÁNDEZ, Humberto (1997): "Del Diccionario a la Enciclopedia: los diccionarios enciclopédicos", en M. Almeida y J. Dorta (eds.), Homenaje al Profesor Ramón Trujillo, Santa Cruz de Tenerife, Montesinos, t. II, pp. 155-164.

LARA, Luis Fernando (1990): "Diccionario de lengua, enciclopedia y diccionario enciclopédico: el sentido de sus distinciones", en Dimensiones de la lexicografia, México, El Colegio de México.

LÁZARO CARRETER, Fernando (1977): Diccionario de términos filológicos, Madrid, Gredos.

MENÉNDEZ PIDAL, Ramón (1945): "El diccionario que deseamos", en Diccionario General Ilustrado de la Lengua Española Vox, Barcelona, Bibliograf.

Moliner, María (1998): Diccionario de uso del español, Madrid, Gredos. Pascual, Jose Antonio, y Olaguibel, M.C., (1991): "Ideología y diccionario", en I. Ahumada (ed.), Diccionarios españoles: contenidos y aplicaciones, Jaén, Universidad de Jaén, pp.73-89.

PEQUEÑO LAROUSSE ILUSTRADO (1998), Barcelona, Larousse.

Porto Dapena, Jose Álvaro (1980): Elementos de Lexicografia. El Diccionario de construcción y régimen de R. J. Cuervo, Bogotá, Instituto Caro y Cuervo. 
QUEMADA, Bernard (1968): Les dictionnaires du français moderne: 15391863, París.

Real ACADEMia Española (1984): Diccionario de la Lengua Española, vigésima ed., 2 vols., Madrid.

- (1992): Diccionario de la Lengua Española, vigésima primera ed., Madrid.

ReY, Alan (1988): Enciclopedias y diccionarios, México, Fondo de Cultura Económica.

REY-DEBOVE, Josette (1971): Etude linguistique et sémiotique des dictionnaires français contemporains, La Haya-París.

SALVÁ, Vicente (1846): Nuevo diccionario de la lengua castellana, París.

SECO, Manuel (1987): “Autoridades literarias en el Tesoro de Covarrubias", en Estudios de lexicografia española, Madrid, Paraninfo, pp. 111-128.

SeCo, Manuel, ANDrés, Olimpia de, y Ramos, Gabino (1999): Diccionario del español actual, 2 vols., Madrid, Aguilar.

TERrERos y PANDO, E. (1786-1793): Diccionario castellano con las voces de ciencias y artes y sus correspondientes en las tres lenguas francesa, latina e italiana, 4 vols., Madrid, Viuda de Ibarra / Benito Cano. Reprod. en facsímil Madrid, Arco Libros, 1987.

WIERZBICKA, A. (1985): Lexicography and Conceptual analysis, Ann Arbor, Karoma Publishers, Inc.

Zgusta, L. (1971): Manual of Lexicography, La Haya-París, Mouton. 